Revista Brasileira de Agricultura Irrigada v.12, nº.5, p. 2897 - 2906, 2018

ISSN 1982-7679 (On-line)

Fortaleza, CE, INOVAGRI - http://www.inovagri.org.br

DOI: $10.7127 /$ rbai.v12n500865

Protocolo 865.18 - 01/01/2018 Aprovado em 03/09/2018

\title{
CRESCIMENTO E FISIOLOGIA DE MELANCIA SUBMETIDA A DOSES DE CINZAS DE BAGAÇO DE CANA
}

Rafael Santiago da Costa ${ }^{1}$, António Fernando de Barros Pereira Pinto ${ }^{2}$, Maria Eliene da Silva Campelo $^{3}$, José Wilson Nascimento de Souza ${ }^{4}$, Ciro de Miranda Pinto ${ }^{5}$, Aiala Vieira Amorim ${ }^{6}$

\section{RESUMO}

Durante a moagem da cana-de-açúcar para a extração do caldo, há geração de bagaço. Esse subproduto é normalmente queimado, gerando cinzas que podem ser utilizadas como insumo fertilizante na agricultura, tornando-se assim uma alternativa ambientalmente correta e economicamente viável para a produção agrícola. Objetivou-se com presente estudo, avaliar o crescimento e as trocas gasosas de plantas de melancia submetidas a diferentes porcentagens de cinza de bagaço de cana-de-açúcar aplicado ao solo. O delineamento experimental foi inteiramente casualizados com 5 tratamentos e 5 repetições. Os tratamentos utilizados foram: $\mathrm{T} 1$ = apenas solo (tratamento referência), $\mathrm{T} 2=$ solo $+3 \%$ de cinzas, $\mathrm{T} 3=$ solo $+6 \%$ de cinzas, $\mathrm{T} 4=$ solo $+9 \%$ de cinzas e T5 $=$ solo $+12 \%$ de cinzas. Ao fim de um período de 60 dias após o plantio, avaliaram-se as seguintes variáveis: altura da planta, diâmetro do caule, comprimento da raiz, número de folhas, área foliar, massa seca da raiz, massa seca do caule, massa seca das folhas, fotossíntese, condutância estomática e transpiração. A utilização de cinzas provenientes da queima do bagaço de cana-de-açúcar aplicadas ao solo favoreceu significativamente no crescimento e nas trocas gasosas das plantas de melancia, onde os tratamentos com 6 e $9 \%$ de cinzas promoveram melhores respostas em todas as variáveis analisadas. Por ser um subproduto agrícola, torna-se uma alternativa viável e eficaz na substituição de insumos químicos para produção de melancia, nas condições edafoclimáticas do Maciço de Baturité, Ceará.

\footnotetext{
${ }^{1}$ Mestrando em Fitotecnia, Universidade Federal do Ceará (UFC) - Campus do Pici, Av. da Universidade, 2853 Benfica, CEP: 60020-180, Fortaleza - CE, Brasil, rafaelsantiagodacosta@yahoo.com.br

${ }^{2}$ Mestrando em Ciência Animal, Universidade Federal do Vale do São Francisco (UNIVASF) - Campus

Ciências Agrárias, Rodovia BR 407, 12 Lote 543, S/N, CEP: 56300-000 - Petrolina - PE, Brasil, nandobp92@hotmail.com

${ }^{3}$ Especialização em Ciência de Alimentos, Instituto Federal do Ceará (IFCE) - Campus Baturité, Av. Ouvidor Vitóriano Soares, 160 - Sanharão, CEP: 62760-000, Baturité - CE, Brasil, eliene_campelo@hotmail.com ${ }^{4}$ Mestrando em Engenharia Agrícola, UFC - Campus do Pici, Av. da Universidade, 2853 - Benfica, CEP: 60020180, Fortaleza - CE, Brasil, wilson.jwns@hotmail.com

${ }^{5}$ Professor Doutor, Instituto de Desenvolvimento Rural (IDR), Universidade da Integração Internacional da Lusofonia Afro-Brasileira (UNILAB), Av. da Abolição, 3 - Centro, CEP: 62790-000, Redenção - CE, Brasil, ciroagron@unilab.edu.br

${ }^{6}$ Professora Doutora, IDR, UNILAB, Av. da Abolição, 3 - Centro, CEP: 62790-000, Redenção - CE, Brasil, aialaamorim@unilab.edu.br
} 
Palavras-chave: biometria, Citrullus lanatus, reutilização de resíduos, trocas gasosas.

\title{
GROWTH AND PHYSIOLOGY OF WATERMELON SUBJECTED TO DOSES OF SUGARCANE BAGASSE ASH
}

\begin{abstract}
During the grinding of the sugar cane juice extraction, there is generation of bagasse. This byproduct is usually burned, creating ash that can be used as fertilizer in agriculture input, thus becoming an alternative environmentally sound and economically viable agricultural production. The aim with this study, to evaluate the growth of watermelon plants subjected to different percentages of gray of bagasse-sugar applied to the soil. The experimental design was completely randomized with 5 treatments and 5 repetitions. The treatments used were: $\mathrm{T} 1=$ only soil (reference), $\mathrm{T} 2=$ soil $+3 \%$ ash, $\mathrm{T} 3=$ soil $+6 \%$ ash, $\mathrm{T} 4=$ soil $+9 \%$ ash and $\mathrm{T} 5=$ soil $+12 \%$ ash. At the end of a period of 60 days after planting, we evaluated the following variables: height of the plant, stem diameter, root length, number of leaves, leaf area, root dry mass, dry mass of the stem, dry mass of leaves, photosynthesis, stomatal conductance and transpiration. The use of ash from the burning of the sugarcane bagasse applied to the soil favored significantly the growth and gas exchange of the watermelon plants, where the treatments of 6 e $9 \%$ of ash promoted better responses in all analyzed variables. For being an agricultural by-product, becomes a viable and effective alternative in the substitution of chemical inputs for watermelon production, soil and climate conditions of the Maciço de Baturité, Ceará.
\end{abstract}

Keywords: biometrics, Citrullus lanatus, reuse waste, gas exchange.

\section{INTRODUÇÃO}

A melancia (Citrullus lanatus (Thunb.) Matsum. e Nakai) é uma planta pertencente à família Cucurbitaceae de grande expressão econômica e social, possuindo propriedades nutricionais e terapêuticas que aumentam o interesse do consumidor pelo seu fruto (DIAS et al., 2006). É originária das regiões secas da África tropical, por isso, desenvolve-se melhor sob condições de clima quente e umidade relativa do ar baixa, com temperaturas variando de 18 a $25^{\circ} \mathrm{C}$ e extremos de 10 a $32^{\circ} \mathrm{C}$ (FELTRIM et al., 2011).

A cultura da melancia é uma das principais espécies olerícolas cultivadas no Brasil, em especial na região Nordeste, por apresentar condições de solo e clima favoráveis ao seu cultivo podendo ser cultivada o ano inteiro sob condições irrigadas (COSTA et al., 2013). No estado do Ceará, devido ao fácil manuseio e menor custo de produção, tem grande importância socioeconômica para os pequenos agricultores da região, sendo cultivada principalmente sob condições de sequeiro (OLIVEIRA et al., 2012a). Assim, estratégias que visem o melhor desenvolvimento vegetal nessas condições, tanto no âmbito biométrico quanto fisiológico, são essenciais para a produção da cultura.

$\mathrm{O}$ crescimento e o desenvolvimento vegetal estão diretamente relacionados com os processos fisiológicos e a utilização correta de adubos na produção. A adubação e a nutrição mineral são fatores essenciais para ganhos na quantidade e qualidade do produto, garantindo retorno adequado, e devem, conforme Oliveira et al. (2012b), ser aplicados corretamente, de modo a auxiliar o pleno desenvolvimento das plantas e atingir elevada eficiência, visando, além de menor custo de produção, um menor dano ambiental.

Vale ressaltar que as funções fisiológicas e bioquímicas também são influenciadas pelo excesso ou a insuficiência de nutrientes, resultando em alterações morfológicas nas 
plantas (TAIZ et al., 2017). A disponibilidade hídrica no solo, bem como os nutrientes disponíveis podem causar fechamento estomático limitando a condutância estomática e a transpiração, o que reduz, consequentemente, a taxa de fotossíntese e a produção das culturas (SILVA et al., 2010).

Segundo Tosta et al. (2010) e Dutra et al. (2016), o uso de adubos orgânicos como fontes de nutrientes para a cultura da melancia ainda é pouco estudado e a sua utilização ainda deve estar associada à adição de fertilizantes minerais, como forma de sustentação da produção, sendo necessário definir os melhores fertilizantes e doses a serem aplicados, no intuito de maximizar os lucros, a produtividade e a qualidade final dos frutos (RAMOS; ARAGÃO, 2010), devendo-se portanto atentarse para subprodutos que viabilizem o desenvolvimento da cultura.

Nessa perspectiva, o uso de subprodutos industriais para formulação de adubos, surge como alternativa viável para a substituição de fertilizantes químicos. Piva et al. (2013), afirmam que a adição de cinza vegetal e de esterco bovino em solo, favorece e auxilia o crescimento da cultura da videira, aumentando o diâmetro do tronco, do ramo e o índice de área foliar. As cinzas de bagaço de cana, por serem ricas em nutrientes, podem ser aproveitadas em solos com baixa fertilidade natural, melhorando as características físico-químicas destes (BONFIM-SILVA et al., 2015).

De acordo com Brunelli e Pisani Júnior (2006), a utilização dessas cinzas como insumo no processo produtivo agrícola, além de ser uma boa fonte de macro e micronutrientes, são também, potencialmente capazes de corrigir o teor de acidez do solo. Mesmo com a importância da reutilização de resíduos para o meio ambiente, ainda são poucos os trabalhos relacionados a essa temática. Neste contexto, objetivou-se com presente trabalho, avaliar o crescimento e as trocas gasosas de plantas de melancia submetidas a diferentes porcentagens de cinza de bagaço de cana-de-açúcar aplicado ao solo.

\section{MATERIAL E MÉTODOS}

O experimento foi conduzido durante o período de julho a outubro de 2013 na Universidade da Integração Internacional da Lusofonia Afro-Brasileira (UNILAB), Campus da Liberdade, localizada no Município de Redenção, Ceará, a uma latitude de 04²13'33' S, longitude de $38^{\circ} 43^{\prime} 50^{\prime \prime}$ W e altitude média em torno de 88 metros. De acordo com a classificação de Köppen, o clima do local é o Aw', ou seja, tropical chuvoso, muito quente.

O delineamento experimental foi em blocos casualizados com 5 tratamentos, 4 blocos e 5 repetições, totalizando 100 plantas. Os tratamentos utilizados foram: $\mathrm{T} 1=$ apenas solo (tratamento referência), $\mathrm{T} 2=$ solo $+3 \%$ de cinzas, $\mathrm{T} 3=$ solo $+6 \%$ de cinzas, $\mathrm{T} 4=$ solo + $9 \%$ de cinzas e $\mathrm{T} 5=$ solo $+12 \%$ de cinzas.

A cinza aplicada foi proveniente do bagaço de cana-de-açúcar queimado no engenho Douradinha, localizado no município de Redenção, Ceará, enquanto que o solo utilizado na mistura dos substratos foi o argissolo, típico da região do Maciço de Baturité. Uma amostra do solo e das cinzas foram enviadas para análise química no laboratório de Química e Fertilidade do Solo da Universidade Federal do Ceará (UFC). Os resultados obtidos estão disponíveis na Tabela 1.

Tabela 1 - Atributos químicos do solo e da cinza utilizados no cultivo da melancia, Redenção - CE, 2013.

\begin{tabular}{|c|c|c|c|c|c|c|c|c|c|c|c|c|c|}
\hline & $\mathrm{C}$ & $\mathrm{N}$ & MO & $\mathrm{C} / \mathrm{N}$ & $\mathrm{Ca}^{2+}$ & $\mathrm{Mg}^{2+}$ & $\mathrm{Na}^{+}$ & $\mathrm{K}^{+}$ & $\mathrm{H}^{+}+\mathrm{Al}^{3+}$ & $\mathrm{Al}^{3+}$ & $\mathrm{T}$ & \multirow{2}{*}{$\begin{array}{c}\mathrm{P} \\
\left(\mathrm{mg} \mathrm{kg}^{-1}\right)\end{array}$} & \multirow[t]{2}{*}{$\mathrm{pH}$} \\
\hline \multicolumn{5}{|c|}{$\left(\mathrm{g} \mathrm{kg}^{-1}\right)$} & \multicolumn{7}{|c|}{$\left(\mathrm{cmol}_{\mathrm{c}} \mathrm{kg}^{-1}\right)$} & & \\
\hline Solo & 20,7 & 2,1 & 20,6 & 10 & 5,3 & 12,4 & 0,3 & 0,4 & 0,7 & 0,3 & 8,8 & 3,28 & 6,3 \\
\hline Cinzas & 31,3 & 1,6 & 0,6 & 19,6 & 40,7 & 24,7 & 4,12 & 36,1 & 0,3 & 0,1 & 7,2 & 6,57 & 6,9 \\
\hline
\end{tabular}

Fonte: Laboratório de Química e Fertilidade do Solo da Universidade Federal do Ceará. 
As mudas de melancia foram produzidas em bandejas de polietileno a partir de sementes comerciais da variedade Crimson Sweet, tendo como substrato areia lavada + húmus de minhoca $(1: 1, v: v)$. Nesta fase, a água era disponibilizada duas vezes ao dia com auxílio de um regador, observando-se a umidade do substrato. Segundo Leão et al. (2008), a variedade Crimson Sweet é uma das mais indicadas, pois responde melhor, se comparada a outros híbridos, às condições que utilizam pouca tecnologia, sendo menos exigente em fertilizantes e tratos culturais.

10 dias após o plantio (DAP), as mudas foram transplantadas para vasos com capacidade de 8 litros contendo $6 \mathrm{~L}$ de solo e cinza, com as proporções previamente estabelecidas pelos tratamentos. Neste período a irrigação era realizada duas vezes ao dia por gotejamento (vazão 4L/h), sendo a lâmina de irrigação calculada com base na evapotranspiração da cultura e estimada a partir da evaporação no tanque Classe A.

Aos 60 DAP foram realizadas medições da taxa fotossintética líquida (A), condutância estomática (gs) e taxa de transpiração (E), em folhas completamente desenvolvidas, no horário entre 9:00 e 12:00 h, sob radiação saturante e sob condições ambientes de temperatura e concentração de $\mathrm{CO}_{2}$, utilizandose um analisador de gás no infravermelho IRGA (LCI System, ADC, Hoddesdom).

Aos 60 DAP, utilizando uma trena graduada em cm, mediu-se também a altura das plantas (AP) a partir do colo da planta até a última inserção foliar e o diâmetro do caule (DC) por meio de um paquímetro digital. Ao final do experimento, as plantas foram coletadas e determinou-se o número de folhas (NF) e a área foliar (AF) por meio de um medidor de superfície (LI - 3100, Área Meter,
Li-Cor., Inc., Lincoln, 87 Nebraska, USA).

Para a obtenção da massa seca do caule (MSC) e das folhas (MSF), a parte aérea foi fracionada onde ambas partes foram coletadas e colocadas para secagem em estufa, com circulação forçada de ar, a $75^{\circ} \mathrm{C}$ até massa constante.

Após a coleta da parte aérea das plantas, o substrato de cultivo dos vasos foi coletado, sendo o seu conteúdo (solo + raízes) peneirado a fim de se separar as raízes do solo. As raízes foram lavadas e identificadas, e pode-se medir seu comprimento (CR) através de uma trena graduada em $\mathrm{cm}$. Em seguida as raízes foram colocadas para secar em estufa, com circulação forçada de ar, a $75^{\circ} \mathrm{C}$ até massa constante, afim de determinar a massa seca da raiz (MSR).

Os dados obtidos foram submetidos a um teste de normalidade, realizando-se em seguida a análise de variância (ANOVA). Posteriormente, quando significativos pelo teste $\mathrm{F}$, submetidos ao teste de médias de Tukey com $\mathrm{P}<0,05$. Para os dados de natureza quantitativos realizou-se uma análise de regressão, as equações que melhor se ajustaram aos dados, foram selecionadas com base na significância dos coeficientes de regressão a 1\% e 5\% de probabilidade pelo teste $\mathrm{F}$ e com maior coeficiente de determinação, ou maior $\mathrm{R}^{2}$. Para as análises estatísticas utilizou-se o programa computacional “ASSISTAT 7.6 BETA”.

\section{RESULTADOS E DISCUSSÃO}

No resumo da análise de variância apresentado na Tabela 2, pode-se observar que todas as variáveis analisadas foram influenciadas significativamente pelos tratamentos, com exceção do comprimento da raiz e da massa seca da raiz.

Tabela 2. Análise de variância para altura de plantas (AP), diâmetro do caule (DC), comprimento da raiz (CR), número de folhas (NF), área foliar (AF), massa seca da raiz (MSR), massa seca do caule (MSC) e massa seca das folhas (MSF) em plantas de melancia (Citrullus lanatus) cultivadas sob doses de cinzas do bagaço de cana-de-açúcar, Redenção - CE, 2013.

\begin{tabular}{|c|c|c|c|c|c|c|c|c|c|}
\hline \multirow{2}{*}{$\begin{array}{l}\text { Fontes de } \\
\text { Variação }\end{array}$} & \multirow[b]{2}{*}{ GL } & \multicolumn{8}{|c|}{ Quadrado Médio } \\
\hline & & $\begin{array}{l}\text { ALT } \\
(\mathrm{cm})\end{array}$ & $\begin{array}{c}\mathrm{DC} \\
(\mathrm{mm})\end{array}$ & $\begin{array}{l}\text { CR } \\
(\mathrm{cm})\end{array}$ & NF & $\begin{array}{c}\mathrm{AF} \\
\left(\mathrm{cm}^{2}\right)\end{array}$ & $\begin{array}{c}\text { MSR } \\
\text { (g) }\end{array}$ & $\begin{array}{c}\text { MSC } \\
\text { (g) }\end{array}$ & $\begin{array}{c}\text { MSF } \\
\text { (g) }\end{array}$ \\
\hline
\end{tabular}




\begin{tabular}{cccccccccc} 
Blocos & 3 & $21,1^{* *}$ & $2,3^{*}$ & $3,4^{\mathrm{ns}}$ & $8,91^{* *}$ & $5,02^{* *}$ & $3,13^{\mathrm{ns}}$ & $7,45^{* *}$ & $4,31^{* *}$ \\
Tratamentos & 4 & $63,9^{*}$ & $6,5^{* *}$ & $8,5^{\mathrm{ns}}$ & $19,9 *$ & $17,4^{* *}$ & $10,6^{\mathrm{ns}}$ & $26,1^{* *}$ & $12,6^{* *}$ \\
Resíduos & 12 & 80 & 0,2 & 40 & 2,9 & 4267,6 & 0,2 & 0,1 & 0,15 \\
Total & 19 & - & - & - & - & - & - & - & - \\
CV (\%) & - & 11,2 & 9,6 & 15 & 11,4 & 19,1 & 9,9 & 21,5 & 19,1 \\
\hline
\end{tabular}

** Significativo pelo teste $\mathrm{F}$ a 0,01 ; * Significativo pelo teste $\mathrm{F}$ a 0,05 ; ${ }^{\text {ns }}$ - não significativo

Para as variáveis altura de plantas e diâmetro do caule, observou-se respostas semelhantes, ajustando-se equações quadráticas, onde as plantas quando submetidas ao tratamento 4 (solo $+9 \%$ de cinzas) apresentaram ponto máximo de 106,94 cm de altura e 5,27 mm de diâmetro do caule.

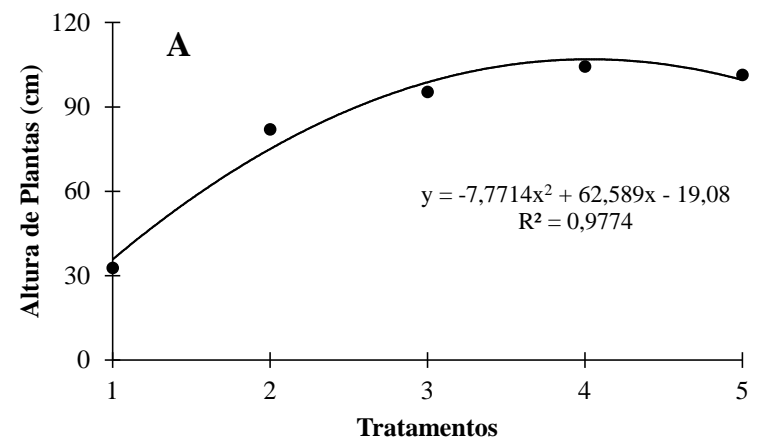

Comparando os pontos mínimos (32,8 cm e 3,9 mm, respectivamente) com os máximos (106,94 cm e 5,27 mm, respectivamente), encontrou-se um acréscimo de 69,32\% para altura e de $26 \%$ para o DC em razão da adição de $9 \%$ de cinzas ao solo (Figura $1 \mathrm{~A}$ e $1 \mathrm{~B})$.

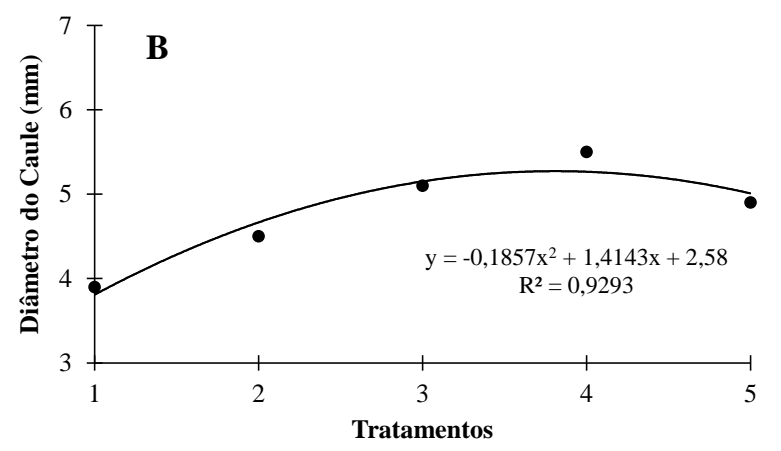

Figura 1. Altura de plantas (A) e diâmetro do caule (B) em plantas de em plantas de melancia (Citrullus lanatus) cultivadas sob doses de cinzas do bagaço de cana-de-açúcar, Redenção - CE, 2013.

Bonfim-Silva et al. (2011), estudando a aplicação de cinza vegetal em Latossolo Vermelho distrófico na cultura Crotalaria juncea, observaram incrementos significativos para as variáveis altura de plantas (75,51\%) e diâmetro do caule $(73,6 \%)$ quando utilizou-se doses de $12,16 \mathrm{~g} \mathrm{dm}^{3}$ e $11,51 \mathrm{~g} \mathrm{dm}^{3}$ de cinza vegetal, corroborando com o presente trabalho. Isso possivelmente ocorreu pelo incremento positivo de nutrientes fornecidos pelas cinzas do bagaço de cana-de-açucar, especialmente de potássio, ao solo e consequentemente às plantas, como pode ser observado na Tabela 1, onde verifica-se maiores teores de $\mathrm{K}$, Ca e $\mathrm{Mg}$ nas cinzas.

Segundo Nogueira et al. (2014), o nitrogênio e o potássio são os dois nutrientes mais exigidos pelas plantas de melancia, e devem ser aplicados de acordo com as exigências de cada cultivar, nível tecnológico, fertilidade do solo, produção esperada, estádio de crescimento e condições climáticas. Resultados semelhantes ao presente trabalho foram encontrados por Flores et al. (2012), que verificaram incrementos significativos para a altura de plantas de cana-deaçucar de acordo com o aumento das doses de potássio, o que confirma seu efeito benéfico para o crescimento das culturas.

Com relação as variáveis número de folhas e área foliar, ajustou-se também duas equações quadráticas. No que diz respeito ao número de folhas, as plantas quando submetidas ao tratamento 3 (solo $+6 \%$ de cinzas) apresentaram ponto máximo de 18,45, cerca de $27,34 \%$ superior ao ponto mínimo $(13,4)$. Já para a área foliar, verificou-se que as plantas do tratamento 4 (solo $+9 \%$ de cinzas) apresentaram ponto máximo de $464,78 \mathrm{~cm}^{2}$, sendo superior ao ponto mínimo $\left(188,2 \mathrm{~cm}^{2}\right)$ cerca de 59,51\% (Figura 2A e 2B). 

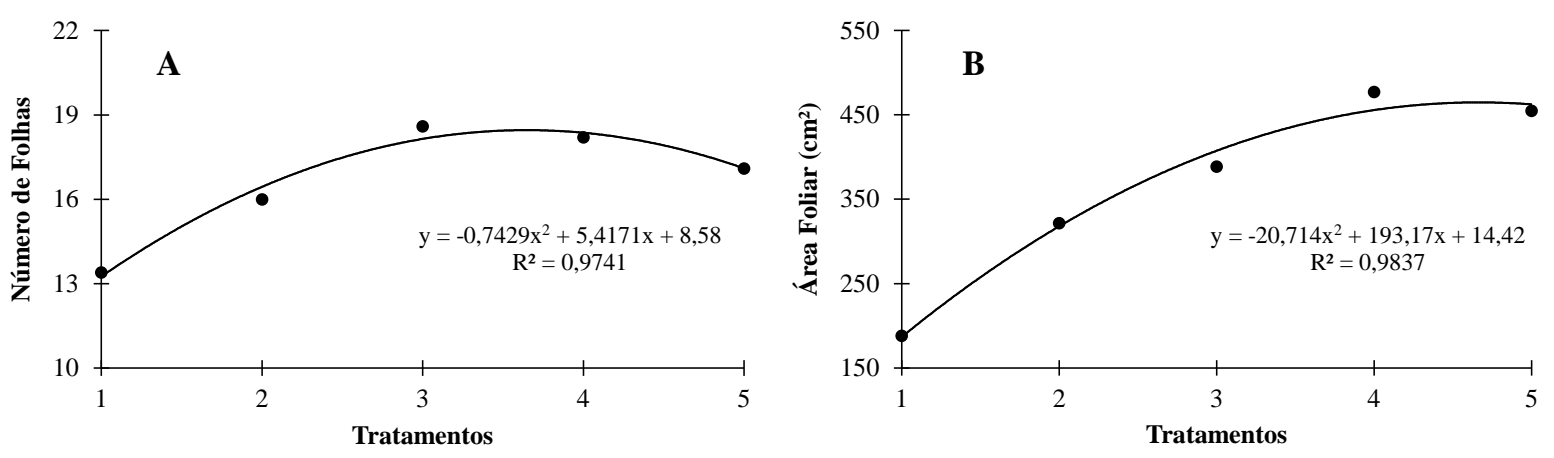

Figura 2. Número de folhas (A) e área foliar (B) em plantas de em plantas de melancia (Citrullus lanatus) cultivadas sob doses de cinzas do bagaço de cana-de-açúcar, Redenção - CE, 2013.

De acordo com Severino et al. (2006), dependendo de sua origem, a cinza pode apresentar quantidades elevadas de nutrientes, o que dá margem para adotar o seu uso na agricultura, uma vez que possuem concentrações relativamente elevadas de elementos minerais. Então, os resultados superiores verificados para as variáveis número de folhas e área foliar, no tratamento 4, estão relacionados com a disponibilidade de nutrientes fornecidos pela cinza do bagaço de cana-de-açúcar. Segundo Taiz et al. (2017), as plantas requerem quantidades expressivas de nutrientes para que possam expressar todo seu potencial produtivo.

Nessa perspectiva, Piva et al. (2013) ao estudarem a cultura da videira, observaram que a adição de cinza vegetal e de esterco bovino

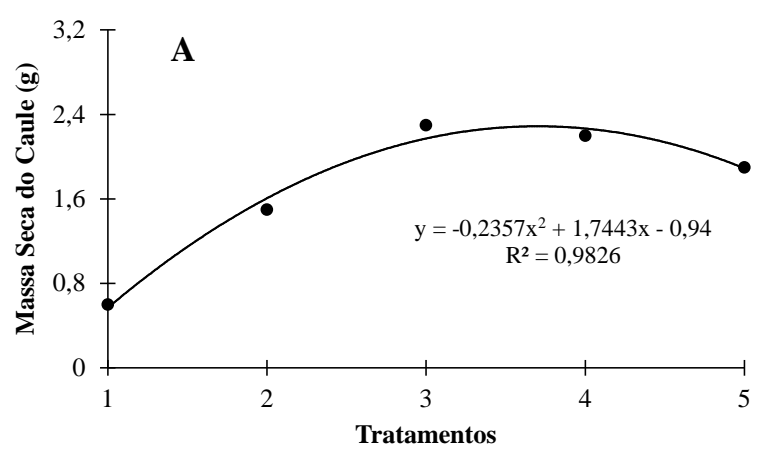

Figura 3. Massa seca do caule (A) e massa seca das folhas (B) em plantas de em plantas de melancia (Citrullus lanatus) cultivadas sob doses de cinzas do bagaço de cana-de-açúcar, Redenção - CE, 2013.

Bonfim-Silva et al. (2011), estudando a aplicação de cinza vegetal em Latossolo Vermelho distrófico, observaram que houve aumentos significativos na cultura de Crotalária juncea, incrementando a produção de massa seca da parte aérea em 89,38\%.

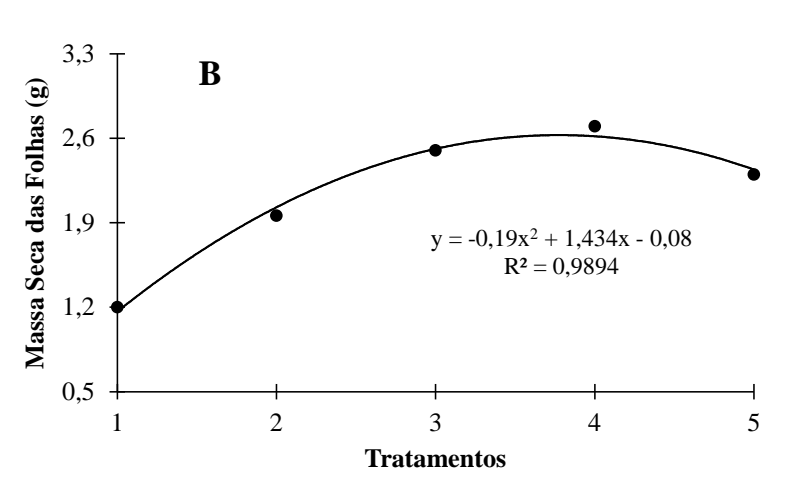

em solo, favoreceu o aumento do índice de área foliar. Da mesma forma, Araújo et al. (2011), trabalhando com melancia sob diferentes doses de $\mathrm{N}$, verificaram que a cultura apresentou resposta linear para o número de folhas, de acordo com o aumento das doses desse nutriente.

Já para as variáveis massa seca do caule e massa seca das folhas, ajustouse duas equações de regressão, onde as plantas de melancia quando submetidas aos tratamentos 3 e 4 apresentaram pontos máximos de 2,29 g para a MSC e 2,63 g para MSF. Fazendo uma comparação com os ponto mínimos (0,6 g e 1,2g, respectivamente), encontrou-se um incremento de $73,79 \%$ para a MSC e de $54,37 \%$ para a MSF (Figura 3A e 3B). 
Silva et al. (2013b), que trabalhando com Vigna unguiculata, observaram incremento significativo para massa seca de caule com o aumento nas doses de biofertilizante. Isso demonstra a importância da adubação para o acúmulo de fitomassa das plantas.

Em relação as variáveis fisiológicas, pode-se observar que apenas a variável transpiração não sofreu influência significativa em relação aos tratamentos aplicados, já a condutância estomática e a fotossíntese foram influenciados significativamente ao nível de probabilidade de 1 e $5 \%$, respecivamente, pelo teste F (Tabela 3).

Tabela 3. Análise de variância para transpiração (E), condutância estomática (gs) e fotossíntese (A) em plantas de melancia (Citrullus lanatus) cultivadas sob doses de cinzas do bagaço de cana-de-açúcar, Redenção - CE.

\begin{tabular}{ccccc}
\hline Fontes de & \multirow{2}{*}{ GL } & \multicolumn{3}{c}{ Quadrado Médio } \\
\cline { 3 - 5 } Variação & & Transpiração (E) & Condutância (gs) & Fotossíntese (A) \\
\hline Blocos & 3 & $0,08 \mathrm{~ns}$ & $3,2 \mathrm{~ns}$ & $3,8 \mathrm{~ns}$ \\
Tratamentos & 4 & $0,57 \mathrm{~ns}$ & $13,3^{* *}$ & $16,2^{*}$ \\
Resíduos & 12 & 1075,4 & 0,01 & 17,2 \\
Total & 19 & - & - & - \\
CV $(\%)$ & - & 15,58 & 68,22 & 50,61 \\
\hline
\end{tabular}

** Significativo pelo teste F a 0,01; * Significativo pelo teste $\mathrm{F}$ a 0,05 ; ${ }^{\text {ns }}$ - não significativo.

No que diz respeito a condutância estomática e a fotossíntese, verificou-se respostas semelhantes para ambas variáveis, onde o tratamento 4 (solo $+9 \%$ de cinzas) apresentaram os pontos máximos de $0,34 \mathrm{~mol}$ $\mathrm{m}^{2} \mathrm{~s}^{-1}$ para condutância estomática e 15,07

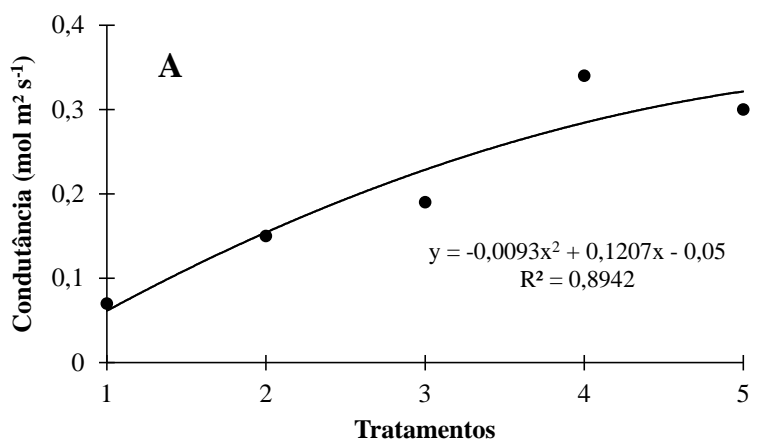

Figura 4. Condutância estomática (A) e fotossíntese (B) em plantas de em plantas de melancia (Citrullus lanatus) cultivadas sob doses de cinzas do bagaço de cana-de-açúcar, Redenção - CE, 2013.

Esses dados obtidos no presente trabalho evidenciam que ao melhorar as características físico-químicas dos solos, as cinzas do bagaço de cana-de-açúcar, bem como outros compostos orgânicos, proporcionaram maiores médias nas taxas fotossintéticas (FEITOSA et al., 2009; GONDIM et al., 2015). Então, os efeitos da cinza na condutância estomática e na fotossíntese devem-se, provavelmente, ao fato $\mu \mathrm{mol} \mathrm{m} \mathrm{m}^{2} \mathrm{~s}^{-1}$ para a fotossíntese. Fazendo uma comparação dos pontos mínimos $\left(0,07 \mathrm{~mol} \mathrm{~m}^{2}\right.$ $\mathrm{s}^{-1}$ e 3,5 $\mu$ mol $\mathrm{m}^{2} \mathrm{~s}^{-1}$ ) observou-se um incremento de $79,41 \%$ para condutância estomática e 76,77 para a fotossíntese (Figura 4A e 4B).

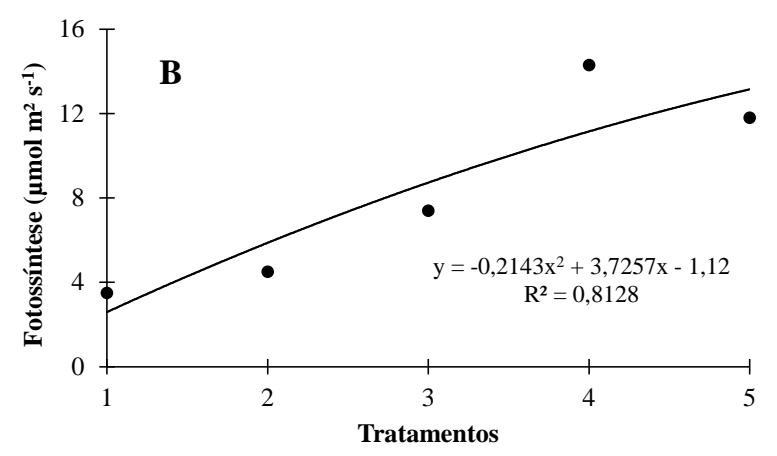

de a cinza atuar como fonte principalmente de potássio, uma vez que esse elemento participa de importantes funções fisiológicas e bioquímicas na planta, como: ativação enzimática, síntese de proteínas, extensão celular, osmorregulação, abertura e fechamento dos estômatos (ROMHELD; KIRKBY, 2010).

Estudos relacionados a efeitos da aplicação da cinza na atividade fisiológica das 
plantas são relativamente escassos (YAMANE, 2013). Algumas pesquisas foram realizadas, objetivando avaliar a influência da sua aplicação nos pigmentos fotossintéticos nas folhas das plantas, como por exemplo, o experimento de Gupta et al. (2007) que trabalhando com feijão comum semeado em vasos preenchidos com solo tratado com diferentes concentrações de cinza de carvão (testemunha, $10 \%$ e $25 \%$ de cinza), observaram que os conteúdos de clorofila a e b e clorofila total foram maiores no tratamento que recebeu a dose mais elevada de cinza.

Então, os resultados positivos para as variáveis fisiológicas quando as plantas receberam doses de cinzas, podem ser atribuídos a presença de nutrientes nesse resíduo, os quais são necessários para a biossíntese de clorofila, especialmente de Mg, constituinte básico dessa molécula.

\section{CONCLUSÕES}

A utilização de cinzas provenientes da queima do bagaço de cana-de-açúcar aplicadas ao solo favoreceu o crescimento e as trocas gasosas das plantas de melancia.

A porcentagem de $9 \%$ de cinzas adicionadas ao solo é a mais indicadas para o cultivo de melancia, tendo em vista que com ela as plantas apresentaram melhores respostas.

Por ser um subproduto agrícola eficaz e uma alternativa viável, indica-se o uso de cinzas do bagaço de cana-de-açúcar para produção de melancia.

\section{REFERÊNCIAS BIBLIOGRÁFICAS}

ARAÚJO, W. F.; BARROS, M. M.; MEDEIROS, R. D.; CHAGAS, E. A.; NEVES, L. T. B. C. Crescimento e produção de melancia submetida a doses de nitrogênio. Revista Caatinga, v.24, n.4, p. 80-85, 2011.

BONFIM-SILVA, E. M.; CARVALHO, J. M. G.; PEREIRA, M. T. J.; SILVA, T. J. A. Cinza vegetal na adubação de plantas de algodoeiro em Latossolo Vermelho do Cerrado.
Enciclopédia Biosfera, Centro Científico

Conhecer, v.11, n.21, p.523-533, 2015.

BONFIM-SILVA, E. M.; SILVA, T. D.; GUIMARÃES, A. C. P.; POLIZEL, A. C. Desenvolvimento e produção de Crotalária juncea adubada com cinza vegetal. Enciclopédia Biosfera, Centro Científico Conhecer, v.7, n.12, p.1-10, 2011.

BRUNELLI, A. M. M. P.; PISANI JÚNIOR, R. Proposta de disposição de resíduo gerado a partir da queima do bagaço de cana em caldeiras como fonte de nutriente e corretivo do solo. In: Congreso Interamericano de Ingeniería Sanitaria y Ambiental, 30 (AIDIS), Anais... Salvador: 2006. p.1-8.

COSTA, A. R.; MEDEIROS, J. F., PORTO FILHO, F. Q.; SILVA, J. S.; COSTA, F. G.; FREITAS, D. C. Produção e qualidade de melancia cultivada com água de diferentes salinidades e doses de nitrogênio. Revista Brasileira de Engenharia Agrícola e Ambiental, v.17, n.9, p.947-954, 2013. http://dx.doi.org/10.1590/S141543662013000900006.

DIAS, R. C. S.; SILVA, C. M. J.; QUEIROZ, M. A.; COSTA, N. D.; SOUZA, F. F.; SANTOS, M. H.; MEDEIROS, K. N. Desempenho agronômico de linhas de melancia com resistência ao oídio. Horticultura Brasileira, v.24, n.1, p.1416-1418, 2006.

DUTRA, K. O. G.; CAVALCANTE, S. N.; VIEIRA, I. G. S.; COSTA, J. C. F.; ANDRADE, R. A adubação orgânica no cultivo da melancieira cv. Crimson Sweet. Revista Brasileira de Agropecuária Sustentável, v.6, n.1, p.34-45, 2016. 10.21206/rbas.v6i1.323.

FEITOSA, D. G.; MALTONI, K. L.; SILVIA, I. P. F. Avaliação da cinza, oriunda da queima do bagaço da cana de açúcar, na substituição da adubação química convencional para produção de alimentos e preservação do meio ambiente. Revista Brasileira de agroecologia, v.4, n.2, p.2412-2415, 2009. 
FELTRIM, A. L.; CECÍlIO FILHO, A. B.; GONSALVES, M. V.; PAVANI, L. C.; BARBOSA, J. C.; CORTEZ, J. W. M. Distancia entre plantas y dosis de nitrógeno y potasio en sandía sin semillas fertirrigada. Pesquisa Agropecuária Brasileira, v.46, n.9, p.985-991, 2011. http://dx.doi.org/10.1590/S0100204X2011000900003.

FLORES, R. A.; PRADO, R. M., POLITI, L. S.; ALMEIDA, T. B. F. Potássio no desenvolvimento inicial da soqueira de cana crua. Pesquisa Agropecuária Tropical, v.42, n.1, p.106-111, 2012. http://dx.doi.org/10.1590/S198340632012000100015.

GONDIM, A. R. O.; SANTOS, J. L. G.; LIRA, R. P.; BRITO, M. E. B.; PEREIRA, F. H. F. Atividade fotossintética da beterraba submetidas a adubação mineral e esterco bovino. Revista Verde de Agroecologia e Desenvolvimento Sustentável, v.10, n.2, p.6165, 2015. https://doi.org/10.18378/rvads.v10i2.3438

GUPTA, A. K.; DWIVEDI, S.; SINHA, S.; TRIPATHI, R. D.; RAI, U. N.; SINGH, S. N. Metal accumulation and growth performance of Phaseolus vulgaris grown in fly ash amended soil. Bioresource Technology, v.98, n.17, p.3404-3407, 2007. 10.1016/j.biortech.2006.08.016.

LEÃO, D. S. S. PEIXOTO, J. R.; VIEIRA, J. V.; CECÍlIO FILHO, A. B. Produtividade de melancia em diferentes níveis de adubação química e orgânica. Bioscience Jornal, v.24, n.4, p.32-41, 2008.

NOGUEIRA, F. P.; SILVA, M. V. T.; OLIVEIRA, F. L.; CHAVES, S. W. P.; MEDEIROS, J. F. Crescimento e marcha de absorção de nutrientes da melancieira fertirrigada com diferentes doses de $\mathrm{N}$ e $\mathrm{K}$. Revista Verde de Agroecologia e Desenvolvimento Sustentável, v.9, n.3, p.3542, 2014.
OLIVEIRA, L. C.; STANGARLIN, J. R.; LANA, M. C.; SIMON, D. N.; ZIMMERMANN, A. Influência de adubações e manejo de adubo verde nos atributos biológicos de solo cultivado com alface (Lactuca sativa L.) em sistema de cultivo orgânico. Arquivos do Instituto Biológico, v.79, n.4, p.557-565, 2012b. http://dx.doi.org/10.1590/S180816572012000400013.

OLIVEIRA, P. G. F.; MOREIRA, O. D. C.; BRANCO, L.; COSTA, R. N.; DIAS, C. N. Eficiência de uso dos fatores de produção água e potássio na cultura da melancia irrigada com água de reúso. Revista Brasileira de Engenharia Agrícola e Ambiental, v.16, n.2, p.153-158, 2012a. http://dx.doi.org/10.1590/S141543662012000200004.

PIVA, R.; BOTELHO, R. V.; ORTOLAN, C.; MÜLLER, M. M. L.; KAWAKAMI, J. Adubação em vinhedo orgânico da cV. Isabel utilizando cinzas vegetais e esterco bovino. Revista Brasileira de Fruticultura, v.35, n.2, p.600-615, 2013. http://dx.doi.org/10.1590/S010029452013000200033.

RAMOS, A. R. P.; ARAGÃO, C. Qualidade de frutos de melancia sob diferentes densidades de plantio. Horticultura Brasileira, v.27, n.2, p.182-188, 2010.

ROMHELD, V.; KIRKBY, E. A. Research on potassium in agriculture: needs and prospects. Plant and Soil, v.335, n.1, p.155-180, 2010. 10.1007/s11104-010-0520-1.

SEVERINO, L. S.; LIMA, R. L. S.; BELTRÃO, N. E. M. Composição química de onze materiais orgânicos utilizados em substratos para produção de mudas. Campina Grande, Embrapa Algodão, Comunicado Técnico, n. 278, 2006.

SILVA, C. D. S.; SANTOS, P. A. A.; LIRA, J. M. S. L.; AS, M. C. M.; DIAS, C. S. J. Curso diário das trocas gasosas em plantas de feijão- 
caupi submetidas à deficiência hídrica. Revista

Caatinga, v.23, n.4, p.7-13, 2010.

SILVA, F. L. B.; LACERDA, C. F.; NEVES, A. L. R.; SOUSA, G. G.; SOUSA, C. H. C.; FERREIRA, F. J. Irrigação com águas salinas e uso de biofertilizante bovino nas trocas gasosas e produtividade de feijão-de-corda. Irriga, v.18, n.2, p.304-317, 2013b. http://dx.doi.org/10.15809/irriga.2013v18n2p3 04.

SILVA, M. L. N.; OLIVEIRA, F. D. A.; OLIVEIRA, M. K. T.; MAIA, P. M. E.; SILVA, R. C. P.; SILVA, O. M. P. Efeito de biofertilizante bovino aeróbico na cultura do feijão caupi. Agropecuária Científica no Semiárido, v.9, n.1, p.110-116, 2013 a. http://dx.doi.org/10.30969/acsa.v9i1.271.
TAIZ, L.; ZEIGER, E; MOLLER, I. M; MURPHY, A. Fisiologia e Desenvolvimento Vegetal. 6 ed. Porto Alegre: Artmed, 2017. 858p.

TOSTA, M. S.; LEITE, G. A. GÓES, G. B.; MEDEIROS, P. V. Q.; ALENCAR, R. D. Doses e fontes de matéria orgânica no desenvolvimento inicial de mudas de melancia “mickylee”. Revista Verde, v.5, n.2, p.117-122, 2010.

YAMANE, D. R. Desenvolvimento de laranjeira valência e caracterização de atributos do solo sob aplicação de cinza do bagaço de cana. 2013. 95f. Tese (Mestrado em agronomia - Produção Vegetal) Faculdade de Ciências Agrárias e Veterinárias - Unesp, Campus de Jaboticabal. 